\title{
Currículo surdo: a luta contra a hegemonia ouvinte inclusiva
}

\author{
Deaf curriculum: the struggle against the hegemony of inclusive hearing \\ Curriculo sordo: la lucha contra la supremacia oyente inclusiva
}

Recebido: 24/08/2021 | Revisado: 29/08/2021 | Aceito: 02/09/2021 | Publicado: 05/09/2021

\author{
Jackson da Silva Vale \\ ORCID: https://orcid.org/0000-0002-7780-9639 \\ Universidade do Estado do Amazonas, Brasil \\ E-mail: jacksonlibras@gmail.com \\ Lucinete Gadelha da Costa \\ ORCID: https://orcid.org/0000-0002-2433-123X \\ Universidade do Estado do Amazonas, Brasil \\ E-mail: lucinetegadelha@gmail.com \\ Debora Rocha de Souza Vale \\ ORCID: https://orcid.org/0000-0002-9113-050X \\ Universidade do Estado do Amazonas, Brasil \\ E-mail: debysouz@gmail.com
}

\begin{abstract}
Resumo
$\mathrm{O}$ atual currículo escolar inclusivo permeia as escolas de ensino regular, o que propicia reflexões político-pedagógicas para discutir quanto ao universo educacional do Surdo, uma vez que a identidade linguística se diferencia da modalidade oral-auditiva. O nosso objetivo é abordar sobre o currículo escolar inclusivo para os Surdos, e discorrer sobre a luta da comunidade surda contra essa hegemonia curricular. Trata-se de um trabalho teórico, amparado a luz de autores e pesquisares que oportunizam a construção de conhecimentos, diálogos e críticas frente ao recorrente e atual modelo de ensino, ideologias e práticas ao alunado Surdo. Este trabalho surgiu através da disciplina "Concepções e Diretrizes Curriculares nas Ciências", do curso de Mestrado Acadêmico em Educação em Ciências na Amazônia, da Universidade do Estado do Amazonas. Estudos que tratem sobre o currículo escolar inclusivo, e principalmente sobre entender quanto a especificidade educacional do sujeito Surdo, poderá contar com subsídios que colaboram para a desconstrução do atual modelo de educação inclusivo, propiciando assim, a construção para uma educação diferenciada e que realmente contemple a modalidade visual do alunado Surdo. Argumentamos que educação bilíngue e currículo Surdo é a modalidade de ensino necessária ao Surdo, pois volta-se para uma proposta que abraça as especificidades, cultura, língua e história do povo e da comunidade Surda, promovendo verdadeiramente o desenvolvimento de indivíduos cidadãos, oportunizando ainda o direito de realmente estar e fazer parte de um espaço em que o encontro com seus semelhantes e com uma comunidade construa identidades e consciência Surda.
\end{abstract}

Palavras-chave: Surdo; Currículo; Hegemonia ouvinte; Inclusão escolar; Ensino.

\begin{abstract}
The current inclusive school curriculum permeates the regular education schools, which provides politicalpedagogical reflections to discuss the educational universe of the Deaf since the linguistic identity differs from the oral-auditory modality. Our goal is to address the inclusive school curriculum for the Deaf and discuss the struggle of the deaf community against this curriculum hegemony. This is a theoretical work, supported by the light of authors and researchers who provide the opportunity to build knowledge, dialogue, and criticism against the current and recurrent model of education, ideologies, and practices to the Deaf student. This work arose through the discipline "Conceptions and Curriculum Guidelines in Science", of the Academic Master's in Science Education in the Amazon, of the Amazonas State University. Studies that deal with the inclusive school curriculum, and especially about understanding the educational specificity of the Deaf, may have subsidies that contribute to the deconstruction of the current model of inclusive education, thus providing the construction for a differentiated education and that really contemplates the visual modality of the Deaf student. We argue that bilingual education and deaf curriculum is the type of education needed by the deaf because it focuses on a proposal that embraces the specificities, culture, language, and history of the deaf people and community, truly promoting the development of individual citizens, by giving them the right to really be and be part of a space wherein encounter with their fellows and with a community build Deaf identities and consciousness.
\end{abstract}

Keywords: Deaf; Retake; The hegemony of the listener; School inclusion; Teaching.

\section{Resumen}

El actual curriculo escolar inclusivo circula por los centros de enseñanza regulares, proporcionando reflexiones políticas y pedagógicas para discutir el universo educativo de las personas sordas, ya que la identidad linguistica 
difiere de la modalidad oral-auditiva. Nuestro objetivo es abordar el currículo escolar inclusivo para Sordos y discutir la lucha de la comunidad sorda contra esa supremacia curricular. Se trata de un trabajo por base teorica, apoyado por autores y investigadores que brindan oportunidad para construir conocimientos, dialogos y criticas a respecto del actual modelo de enseño, ideologias y practicas a estudiantes Sordos. Este trabajo emergió mediante estudo de la materia "Concepciones y Pautas de Curriculo en Ciencias", en curso de Maestría en Educación en Ciencias de la Amazonia, de la Universidad del Departamento del Amazonas. Estudios al respecto de currículo escolar inclusivo y principalmente de assuntos que tratan de entender sobre la especificidade em educación de personas Sordas, puede apoyarse en subsidios que colaboran para la desconstrucción del actual modelo de educación inclusivo, y proporcionando vistas a eso, construcción para una diferente educación, una que verdaderamente incluya la modalidad visual de los estudiantes Sordos. Discutimos que la escuela bilingue y tambien el tema de curriculo Sordo es la modalidad de enseño que se hace necesario al Sordo, porque se destina a una propuesta que abrasa las especificaciones, cultura, lengua y historia del pueblo y de la comunidad Sorda, promoviendo realmente el desenvolvimiento de ciudadanos, dando oportunidad de derechos para estar y hacer parte de espacios en que encuentros entre semejantes y una comunidad construya identidades y conciencia Sorda.

Palabras clave: Sordo; Curriculo; Supremacia oyente; Inclución escolar; Enseñanza.

\section{Introdução}

O sistema educacional brasileiro sofreu alterações quanto à temática inclusão de alunos com deficiência, abarcando direitos educacionais como o de acesso a escolas de ensino regular e implementação de recursos de acessibilidade. Debates em torno dessa temática tem intensificado a perspectiva de educação especial e inclusiva no nosso pais, principalmente no aspecto de incluir a todos em instituições de ensino regular.

Com a Lei Brasileira de Inclusão, Plano Nacional de Educação, Política Nacional de Educação Especial na Perspectiva da Educação Inclusiva (PNEEPEI) substituída pela Política Nacional de Educação Especial: Equitativa, Inclusiva e com Aprendizado ao Longo da Vida (suspensa pelo STF) e Base Nacional Comum Curricular - BNCC, fica claro toda eliminação de barreiras que façam segregação de alunos com deficiência da rede básica de ensino, o que acarreta inclusão das diversidades e sua integração social.

Ao mesmo tempo em que a igualdade se veste com trajes legais, não se pode afastar a diferença quanto diversidades histórias, de identidades, culturais, sociais e linguísticas, o que remete a refletir se realmente incluir é abraçar todas as diferenças. Acontece que no nosso país, existem os que não aceitam a inclusão educacional em escolas regulares de ensino básico e não se veem contemplados pelo currículo inclusivo dessas escolas, requerendo o direito de igualdade pela diferença e pelas suas especificidades, buscando o direito de construir uma diferenciação curricular e uma pedagógica que venha romper com o paradigma da inclusão escolar em escolas regulares do ensino básico.

Currículo Surdo ${ }^{1}$ visa apresentar não apenas conhecimento de sala de aula, conteúdos, corpo escolar e regras de um sistema educacional, mais do que isso, quer romper com paradigmas hegemônicos que se restringem a formas, moldes e modelos igualitários, apenas pela concepção de igualdade com adaptações.

Currículo Surdo quer utilizar-se de uma modalidade de ensino e aprendizagem através das raízes de uma comunidade e de um povo que se formam por uma língua visual-espacial. A Luta é contra a hegemonia ouvinte e se apresenta pelo movimento Surdo a favor de um povo que grita pelo direito de reconhecimento a sua especificidade, não aceitando a inclusão pela deficiência, mas pela equidade de diferença linguística.

Este trabalho foi elaborado através da disciplina "Concepções e Diretrizes Curriculares nas Ciências", do curso de Mestrado Acadêmico em Educação em Ciências na Amazônia, da Universidade do Estado do Amazonas, e tem por objetivo discutir e propiciar reflexões a respeito do currículo escolar inclusivo das escolas de ensino básico regular, apresentando o aluno Surdo por essa perspectiva de inclusão, colaborando para que povo Surdo seja de fato conhecido e reconhecido pelas

\footnotetext{
1 Neste trabalho, utilizaremos o termo "Surdo" com "S" em maiúsculo e suas variações, como forma de respeito e reconhecimento à cultura Surda, empoderamento, posicionamento político, valores linguísticos e sociais, bem como o processo histórico e cultural que envolve os sujeitos Surdos.
} 
suas diferenças, e para que verdadeiramente ocupe o espaço de encontro com seus semelhantes, com uma comunidade usuária da Língua Brasileira de Sinais, gerando identidades e consciência Surda.

Nesse sentido torna-se pertinente colaborar com a temática de currículo inclusivo, para que não se torne consenso o sentido de que a inclusão serve a todos, muito menos contribuir com a inequívoca proposta de currículo unificado pela hegemonia ouvintista ${ }^{2}$. O que propomos por tanto, é apresentar a modalidade de ensino bilíngue, e discorrer sobre um currículo que contemple as especificidades de cultura, identidade, história e língua do Surdo.

\section{Metodologia}

Para este trabalho, recorremos a pesquisa bibliográfica, que conforme Marconi \& Lakatos (2003, p. 183) "a pesquisa bibliográfica, ou de fontes secundárias, abrange toda bibliografia já tornada pública em relação ao tema de estudo", para isso discorremos a luz de pesquisadores surdos e ouvintes que discutem sobre a educação de surdos, e pela qual carregam conhecimentos e pesquisas a respeito do currículo escolar inclusivo e currículo para os Surdos, educação de Surdos no Brasil e críticas quanto às políticas de inclusão implantadas no país.

Optou-se, por tanto, pelo cunho reflexivo, através da construção de tópicos que abordam e propiciam uma sequência de argumentos que exploram a temática do aluno Surdo inserido no currículo inclusivo da rede de ensino básico de escola regular. A partir dessa argumentação, aborda-se o porquê do clamor de um currículo Surdo e a constante luta pela quebra de uma hegemonia majoritária oral-auditiva, a qual insiste em incluir o Surdo como deficiente.

\section{O Surdo no Currículo Escolar Inclusivo}

O tema de educação especial e inclusiva tem sido destaque de inúmeros debates nacionais e internacionais, e tratar sobre, é englobar aspectos históricos, sociais, culturais, antropológicos, linguísticos, entre outros.

A luz de legislações e diretrizes brasileiras que buscam garantir direitos educacionais, não com a segurança de efetivação, uma vez que a prática vista pela realidade, por vezes, não consegue se aproximar do que está pressuposto em documento, no entanto, o fato é que a universalidade do direito à educação deve ser garantido a todos os seres humanos, independentemente de suas singularidades.

Discutir sobre a inclusão escolar, é inserir em debate temáticas de integração social, cultural, histórica, linguística, étnicos, gênero, condições sócio econômicas e de deficiências, homossexual ou heterossexual, negro ou branco, surdo ou ouvinte $^{3}$, pela qual todos são colocados no mesmo patamar do direito à educação, o que engloba, por consequência, discussões pedagógicas e organizacional, a fim de observar, como se dará essa educação para todos.

Adentramos assim ao que se trata o sistema organizacional, e com essa ideia a questão do que vale a pena ensinar, um planejamento sistémico que envolve o processo educativo, seja social ou pessoal de toda uma comunidade escolar, estamos tratando por tanto do currículo escolar. Para Lopes e Macedo (2011, p. 20) currículo tem diversas definições, e entre as variadas ideias, segue:

[...] o proposto pelas redes de ensino àquilo que acontece em sala de aula tem significado de grade curricular, com disciplinas/atividades e cargas horárias, o conjunto de emendas e programas de disciplinas/atividades, os planos de ensino dos professores, as experiências propostas e vividas pelos alunos. [...] a ideia de organização, prévia ou não, de experiências/situações de aprendizagem realizada por docentes/ redes de ensino de forma a levar a cabo um processo educativo.

\footnotetext{
${ }^{2}$ Utilizamos o termo "ouvintista" com base no autor Skliar (1999, p. 15), pela qual explica que o ouvintismo são representações dos ouvintes sobre a surdez e sobre os Surdos.

${ }^{3}$ Segundo Quadros (2003, p. 89) “o termo "ouvinte" refere-se a todos aqueles que não compartilham as experiências visuais enquanto surdos. Esse termo em oposição ao "surdo" foi uma dicotomia criada pelos próprios surdos intimamente relacionada com a demarcação da diferença."
} 
Definir concepções sobre a palavra currículo, não apenas com o olhar administrativo de sala de aula, mas outras possibilidades de compreender a essência do currículo, é o que caracteriza a construção do conhecimento e diálogos sobre currículo, perspectivas de discursos e saberes em construção, ainda propicia análises frente as disputas políticas-sociaiseducativas.

Visto pela percepção de Silva (2007, p. 15), currículo é uma questão de "identidade" ou de "subjetividade", acontece que ao se discutir sobre currículo, o termo pode remeter a conhecimentos disciplinares, o que propicia a não considerar que currículo "se constitui, se relaciona e envolve naquilo que somos, naquilo que nos tornamos: na nossa identidade e subjetividade, portanto, acabamos por nos tornar o que somos, e além de uma questão de conhecimento, o currículo é também uma questão de identidade".

Quando o currículo circula pelo viés de uma educação inclusiva, é preciso voltar-se para a participação de vozes que convivem nas diferenças e não apenas pelas deficiências, sujeitos que partilham de espaços em comum, e que precisam se sentir como parte desse espaço, propiciando oportunidades de compartilhamento de suas experiências de mundo, e que estas problematizem e levem a refletir sobre o que já está prescrito.

Se o currículo inclusivo visa abraçar a garantia de uma sociedade mais justa e igualitária, podendo não significar que a formação deva colocar os sujeitos exatamente como se fossem idênticos, até porque, o currículo é vivo e se constrói no diálogo democrático o que proporciona oportunidade de convívio educacional e social entre toda uma comunidade escolar.

O que cabe esclarecer é que o currículo não pode se restringir a formas, moldes e modelos igualitários, apenas pela concepção de igualdade, pois há um processo de relações sociais, pela qual a escola precisa propiciar aos seus sujeitos a compreensão de mundo em que estão inseridos, a construção de seu mundo e de sua própria história, e isso acontece através de sua cultura e identidade, oferecendo formas de participação ativa e autônoma nas decisões.

Pela concepção sócioantropológica, o sujeito se concebe pelas suas diferenças e não pela sua deficiência, sendo assim, um currículo em construção e pela construção de um indivíduo social, convive com pessoas de diferentes etnias, classes sociais, sexo, deficiências, línguas, o que oportuniza um conhecer, conviver e respeito as diferenças. O autor Casali (2015, p. 20), discorre sobre conceitos que precisam estar muito bem entendidos:

[...] ocorre que, ao mesmo tempo, há direitos que são diversificados e diferenciados: por exemplo, os direitos específicos das mulheres gestantes, dos idosos, das crianças. Nesses casos a igualdade não se aplica. Era preciso um conceito que relacionasse direitos de igualdade e direitos de diferença. Assim sendo, a equidade refere-se à correção ética e à justiça no modo de se julgar e tratar (aqui entram as políticas públicas) toda e qualquer pessoa, considerandoa nos seus direitos mais universais e ao mesmo tempo mais diferenciados.

É por essa concepção do autor que agora vamos compreender a especificidade do alunado Surdo, tanto pela igualdade quanto pela sua especificidade, tendo em vista que não é possível por nenhum minuto ignorar sua diferença, uma vez que o direito de estar entre o igual e o diferente é essencialmente humano.

A escola que se rege não apenas pela igualdade mas também pelas especificidades, reconhece que o Surdo possui primeiramente uma Língua visual-espacial, e que o canal de aprendizagem é diferente do oral-auditivo, é participante de uma cultura e comunidade que se rege a partir de sujeitos usuários da Língua Brasileira de Sinais.

Essa cultura é multifacetada, mas apresenta características que são específicas, ela é visual, ela traduz-se de forma visual. As formas de organizar o pensamento e a linguagem transcendem as formas ouvintes. Elas são de outra ordem, uma ordem com base visual e por isso têm características que podem ser ininteligíveis aos ouvintes. Ela se manifesta mediante a coletividade que se constitui a partir dos próprios surdos. (Quadros, 2003, p. 86)

Nesse sentido, o currículo inclusivo não abraça essa diferenciação linguística que o aluno Surdo precisa, pois estamos 
tratando de um currículo que tem uma língua de circulação oral-auditiva de uma sociedade ouvinte, e pela qual o Surdo não é usuário.

O que cabe compreender é que o Surdo ao ingressar na escola regular, na maioria das vezes, começa o seu processo de aquisição linguística totalmente diferente de um aluno ouvinte, pois este já ingressa na escola falando e compreendendo que, para ir ao banheiro, é preciso falar palavras que remetam à compreensão de sua necessidade, enquanto que o Surdo possivelmente começará a aprender e compreender esse processo.

Currículo inclusivo para as demais deficiências não requer de uma diferenciação linguística, não querer de uma outra Língua como sendo a primeira língua, pois todos compartilham de uma mesma língua que é a Língua Portuguesa, e por mais difícil que sejam as suas especificidades, acompanham auditivamente ao que se passa no meio escolar, diferentemente do aluno Surdo, que não pode compartilhar das mesmas situações, como por exemplo de um alerta sonoro, de conversas paralelas entre os próprios colegas, e outras situações corriqueiras que constituem um ambiente educacional.

O jornal "O Globo" em 29 de março de 2011, realizou uma entrevista com Profa. Dra. Patrícia Rezende, na época Diretora de Políticas Educacionais da Feneis ${ }^{4}$, na qual a professora denunciou que não havia compartilhamento de língua nas escolas convencionais, cabe apresentar um trecho dessa entrevista, para questionarmos quanto ao tema:

A atual política de inclusão insiste em colocar crianças surdas junto com as ouvintes, sem haver um compartilhamento linguístico entre elas. Nesses espaços, as crianças surdas oriundas de famílias ouvintes não adquirem sua língua natural de forma espontânea, como as crianças ouvintes que compartilham a mesma língua da sua família interagindo e obtendo informações e, assim, construindo o conhecimento de mundo, que é aprofundado na escola. Como haver inclusão se não há aquisição linguística pela criança surda? (Campello \& Rezende, 2014, p. 76)

A Língua Brasileira de Sinais é a corporação de uma identidade pessoal e cultural, fazendo parte da constituição do Surdo, de sua forma de pensar, organizar e expressar, por tanto, não se pode pensar a Língua como algo apartado do sujeito, e se a Língua do sujeito Surdo é a Libras, então se torna inviável coloca-la apenas como inclusivo, mero apoio como recurso educacional. Sacks (1998, p. 86) observa:

Pois na língua de um povo, observa Herder, "reside toda a sua esfera de pensamento, sua tradição, história, religião e base da vida, todo o seu coração e sua alma". Isso vale especialmente para língua de sinais, porque ela é a voz - não só biológica, mas cultural, e impossível de silenciar - dos surdos.

Todo esse poder que uma língua carrega, não pode estar apenas depositada em um único profissional, como se apenas isso fosse o suficiente, pois ainda se carrega a crença limitante e errônea de que o profissional Tradutor e Intérprete de Libras é o recurso que o Surdo precisa, por tanto, visto como recurso inclusivo, esta é a proposta que a educação inclusiva dispõe aos alunos Surdos.

No entanto, esse profissional não carrega consigo toda uma cultura surda, não se pode ater a um único profissional a existência social escolar e curricular, muito menos representar uma solução do processo de aquisição linguística, uma vez que não possui a formação pedagógica, metodológica e didática para alfabetizar. Souza, apud Moreira e Candau (2010, p. 44) explicam que:

As pessoas têm direito à igualdade sempre que a diferença as tornar inferiores, mas têm direito à diferença sempre que a igualdade ameaçar suas identidades. Será que em nossas escolas e em nossas salas de aula ainda caminhamos, com nossas práticas, na direção de anular aspectos das identidades dos/as estudantes? Será que os processos de homogeneização que muitas vezes promovemos, por meio do currículo, dos procedimentos didáticos, das relações pedagógicas e da avaliação, contribuem, de algum modo, para consolidar as relações de poder que atravessam as diferenças presentes no seio de nosso alunado?

\footnotetext{
${ }^{4}$ Filiada à Federação Mundial dos Surdos, a Federação Nacional de Educação e Integração dos Surdos (Feneis) é uma entidade filantrópica sem fins lucrativos de apoio à Comunidade Surda.
} 
Currículo inclusivo inviabiliza construção de saberes, identidades, conhecimento cultural, social e histórico do próprio Surdo, uma vez que sua percepção de aprendizado, interação social, cultural e principalmente linguística acontece diferentemente do ouvir, é portanto que falaremos a seguir do currículo surdo.

\section{Porque Currículo Surdo}

Reconhecer as diferenças no âmbito educacional, é buscar garantir equidade de acesso à educação, e isso abraça a diferença linguística, e consequentemente um currículo voltado para a sua modalidade. Se tratando de aluno Surdo, a modalidade linguística é visual-espacial, e portanto, o currículo deve ser construído pela perspectiva visual.

O currículo surdo incorpora experiências visuais, estas perpassam o simples ato de ver, e incorpora diretamente uma instrução direta na língua soberana da comunidade Surda, a esse sentido Freire (2014, p. 116) diz que "a educação autêntica, repitamos, não se faz de A para B ou de A sobre B, mas de A com B, mediatizados pelo mundo", sendo assim, não se pode falar deles sem eles. As autoras Campello e Rezende (2014, p. 78) se posicionam quanto a essa afirmação:

Nós, os surdos, não queremos ser tutelados, queremos o exercício da liberdade pela forma e escolha linguística e cultural condizente com o nosso modo de viver e experienciar, de sermos surdos, diferente dos ouvintes. Somente nós, surdos, que sabemos o que é melhor para nós, da forma como precisamos ser educados, da forma como precisamos aprender.

Por esse motivo que o currículo deve estar organizado partindo da perspectiva visual-espacial, e para que o currículo seja Surdo, a escola precisa ter uma identidade bilíngue, sendo a Língua Brasileira de Sinais como a primeira língua (L1) de convívio e instrução, e como segunda língua (L2) a Língua Portuguesa escrita.

O currículo surdo disponibiliza aos alunos experiências visuais, que incorporam a história de uma comunidade viva, ativa e atuante socialmente, uma comunidade que luta pela construção de conhecimentos voltados verdadeiramente para o uso da língua em todos os espaços e por todos os membros e corpo escolar, inclusive da família do próprio aluno Surdo, reforçando o cumprimento do papel social em tornar os alunos conhecedores e defensores dos seus direitos e do povo Surdo, de sua cultura e de sua herança linguística, cidadãos e cumpridores dos seus deveres.

Acrescenta-se a proposta de currículo surdo as manifestações culturais Surda/s, assim como as manifestações culturais para ouvinte se realizam em cantorias, musicas, entre outros, as manifestações que verdadeiramente atendem aos Surdos podem ser pintura, escultura, poesia Surda, narrativas de histórias, lendas e contos adequados ao povo Surdo, isso também ocorre com o teatro, piadas, humor, cinema, história em quadrinhos, dança e artes visuais, entre outros, deixando um currículo a qual tudo precisa ser adaptado, para assumir um currículo adequado a comunidade e ao povo Surdo.

Faz-se necessário um currículo que ofereça-lhes sua construção cultural e histórica, um currículo que não tenta normalizar o surdo, mas sim problematizar sua diferença. Segundo Feneis (1999)5:

É importante que a escola insira no currículo as manifestações das cultura/s surda/s: pintura, escultura, poesia, narrativas de história, teatro, piadas, humor, cinema, história em quadrinhos, dança e artes visuais, em sinais. A implantação de laboratórios de cultura surda se faz necessária. Conhecer a história surda e seu patrimônio, os quais proporcionam o estabelecimento de sua identidade surda.

Formozo (2008) explica que a cultura surda foi desrespeitada durante muito tempo. Através de práticas ouvintistas o surdo era narrado e obrigado a narrar-se a partir de uma referência ouvinte. O ouvintismo foi - e ainda é - um mecanismo de poder-saber, pois estabelece uma relação de poder do ouvinte que construiu um saber sobre o surdo, narrando-o como alguém a

${ }^{5}$ Esse documento foi elaborado por aproximadamente 150 surdos que participaram do Pré-congresso relativo ao V Congresso Latino Americano de Educação Bilíngue para Surdos, em Porto Alegre (RS), no ano de 1999, e estabelece 147 diretrizes para a educação de surdos no Brasil, havendo uma versão revisada do mesmo documento (FENEIS, 2005), na qual foi entregue ao governo do Estado do Rio Grande do Sul. 
quem falta algo, alguém que deve ser normalizado, gerando com isso uma vergonha aleia, vergonha para a comunidade ouvintista que não aceita a especificidade linguística do surdo.

Arroyo (2013) lembra que é necessário reconhecer os educando como sujeitos ativos-afirmativos. Ao se conceber uma proposta curricular devemos reconhecer a singularidade dos sujeitos, o que leva a escola a pensar a sua prática e reinventar as suas ações. É reconhecer a voz dos estudantes e não trata-los como meros objetos.

Proporcionar o conhecimento histórico Surdo e seu patrimônio, proporciona o estabelecimento de identidades Surdas. Formozo (2008, p. 47) explica que não existe apenas uma identidade Surda fixa:

Além de surdos, também são mulheres, homens, homossexuais, heterossexuais, pobres, ricos, negros, brancos e ainda a mistura de várias dessas características. Jamais dois surdos serão iguais pelo simples fato de serem surdos. A maneira de posicionar-se como surdo pode ser diferente para cada um. As identidades são produzidas pela linguagem e modificam-se no tempo e no espaço através das relações de poder.

Por isso que a educação de Surdos tem que estar submetida a um currículo que possibilite um espaço que permita se olharem e se reconhecerem como Surdos, sujeitos representantes de um grupo étnico-cultural específico. Godson (1995) assevera que:

Diferentes currículos produzem diferentes pessoas, mas naturalmente essas diferenças não são meras diferenças individuais, mas diferenças sociais, ligadas à classe, à raça, ao gênero. O currículo deve ser visto como produzindo identidade e subjetividades sociais determinadas. O currículo não apenas representa, ele faz; é preciso reconhecer que a inclusão ou exclusão no currículo tem conexões diretas com a inclusão ou exclusão na sociedade.

Com isso, assume-se a importância do currículo carregar identidades Surdas, e as diferenças sociais que o povo Surdo reivindica por meio de lutas e representações políticas. Um outro viés de importância no currículo Surdo refere-se a sala de aula e a maneira de como os conteúdos são ministrados, estamos querendo mostrar a relação do olhar com o espaço, espaço como experiência visual no ensino/aprendizagem, uma vez que um dos parâmetros gramaticais da Língua Brasileira de Sinais é composta pela utilização do espaço. Quadros (2003, p. 93) explica:

As experiências visuais são as que perpassam a visão. O que é importante é ver, estabelecer as relações de olhar (que começam na relação que os pais surdos estabelecem com os seus bebês), usar a direção do olhar para marcar as relações gramaticais, ou seja, as relações entre as partes que formam o discurso. O visual é o que importa. A experiência é visual desde o ponto de vista físico (os encontros, as festas, as estórias, as casas, os equipamentos...) até o ponto de vista mental (a língua, os sonhos, os pensamentos, as ideias...). Como consequência é possível dizer que a cultura é visual. As produções linguísticas, artísticas, científicas e as relações sociais são visuais.

Esse processo de reconhecimento cultural, social, linguístico, de identidades, e de visualidade requer também a observância dos interlocutores que a criança Surda terá nessa interação escolar, sendo assim, é de suma importância que toda a comunidade escolar seja partícipe no meio da comunidade Surda e que conheçam a experiência visual Surda e suas formas de pensamento, expressos através de uma língua visual-espacial: a Língua de Sinais, e isso só é possível se todos os membros do corpo escolar forem usuários da Língua, sendo esta a L1 da escola.

A Língua portuguesa, por tanto, passa a compor o currículo escolar como L2 na modalidade escrita, esta afirmação é explicada por Quadros (2003, p. 100):

Um dos problemas que deve ser reconhecido é que a escrita alfabética da língua portuguesa no Brasil não serve para representar significação com conceitos elaborados na língua de sinais brasileira, uma língua visual espacial. Um grafema, uma sílaba, uma palavra escrita no português não apresentam nenhuma analogia com um fonema, uma sílaba e uma palavra na língua de sinais brasileira, mas sim com o português falado. 
O currículo Surdo diferente de um currículo inclusivo, abraça políticas linguísticas educacionais e não políticas inclusivas educacionais, por isso o currículo Surdo está associada a educação bilíngue de Surdos e dissociada dos princípios epistemológicos de educação inclusiva.

O recente Decreto $\mathrm{n}^{\circ}$ 10.502, de 30 de setembro de 2020, que instituía a Política Nacional de Educação Especial: Equitativa, Inclusiva e com Aprendizado ao Longo da Vida, gerou críticas e repúdios a nível nacional por parte de diversas entidades, no entanto, o Instituto Nacional de Educação de Surdos - INES, a Federação Nacional de Educação e Integração dos Surdos - (Feneis) e instituições apoiadores a causa Surda em busca de políticas educacionais bilíngue, apoiavam o PNEE, uma vez que o regulamento garantia, de fato, o que poderia ser uma educação para os Surdos: a educação bilíngue.

Para a comunidade Surda, a PNEE (2020) definia uma conquista educacional, tendo em vista a proposta de educação bilíngue de Surdos como uma modalidade escolar, reconhecendo assim as especificidades do ensino bilíngue, assim como acontece na modalidade de educação indígena, oferecendo a oportunidade de escolha quanto à abordagem educacional mais adequada para cada estudante, o que não estava contemplado na anterior Política Nacional de Educação Especial (2008), uma vez que impunha um modelo educacional único a todos os indivíduos com deficiência, e claro os Surdos mais uma vez vistos pela deficiência clínica, não focando nas singularidades.

Em seis de outubro do mesmo ano da publicação da PNEE (2020), a Feneis informou mediante nota de apoio e esclarecimento $^{6}$, que as comunidades Surdas brasileiras vinham lutando pela inclusão da educação bilíngue de Surdos nas políticas educacionais, assim como pela inclusão de políticas linguísticas a essa discussão, e pela qual o Decreto definiu e abordou várias questões relacionadas à educação bilíngue de Surdos:

À vista disso, as escolas e classes bilíngues de surdos, constituídas por estudantes surdos, surdocegos, com deficiência auditiva sinalizantes, com altas habilidades ou superdotação, assim como com outras deficiências, como preconiza o decreto em tela, são espaços de extrema relevância, pois constituem um ambiente linguístico adequado, que promove a identidade linguística de bebês, crianças, jovens e adultos surdos e a equidade de condições de aprendizagem, sem a necessidade da presença de tradutor-intérprete de língua de sinais em sala de aula, considerando que as aulas são ministradas por professores comprovadamente bilíngues, sendo, a Libras, novamente, a língua de INSTRUÇÃO, ENSINO, COMUNICAÇÃO e INTERAÇÃO.

Uma Escola Bilíngue de Surdos é inclusiva, pois inclui os surdos com seus pares, de forma, inclusive, a identificar nos surdos mais velhos modelos bem sucedidos, oferece a escolarização e permite-lhes competir igualitariamente com outros cidadãos não surdos, porque têm garantida a equidade. Constata-se nessa nova política a preocupação em não deixar ninguém para trás. (Feneis, 2020, p. 01)

O que queremos esclarecer, é que a comunidade Surda busca o direito de se desvincular da educação especial em escolas inclusivas, de romper com os parâmetros e diretrizes curriculares de adaptações e acessibilidade, uma luta pela busca da equidade a qual carrega a singularidade de alcançar a igualdade no direito à educação de forma plena e igualitária, o que implica em políticas linguísticas e educação bilíngue.

Somos uma minoria linguística na luta pela preservação da língua de sinais e sua instituição como língua de instrução em nossa educação; não queremos a educação inclusiva como é preconizada, e muito menos a educação especial, queremos uma educação linguística, uma política linguística traçada pelo nosso "ser surdo". (Campello \& Rezende, 2014, p. 88)

As autoras intensificam ainda mais a luta de décadas pelo reconhecimento educacional linguístico bilíngue e não inclusivo. A inclusão de estudantes Surdos nas classes comuns em escola regular, seguindo um currículo regido por uma hegemonia ouvintista, não significa ofertar condições iguais de acesso à educação, por tanto, não garante necessariamente, o respeito à diversidade ou o desenvolvimento de todas as potencialidades do Surdo.

\footnotetext{
${ }^{6} \mathrm{https}: / / \mathrm{www}$. idea.ufscar.br/arquivos/politicas-eesp/feneis.pdf
} 


\section{A Luta Contra a Hegemonia Ouvinte}

Tratar de educação é também refletir sobre os artefatos políticos, econômicos, sociais e culturais, que, de forma intrínseca, tendem a padronizar o processo de escolarização, determinando os saberes e conhecimentos a serem ensinados. Apple (2013, p. 49) nos explica que umas das perguntas mais fundamentais sobre o processo de escolarização é “Que tipo de conhecimento vale mais?” posteriormente o autor reformula essa pergunta para aprofundar um debate político educacional, sendo “o conhecimento de quem vale mais?”, questionamentos com bases ideológicas e políticas.

Pensar no ser Surdo é refletir sobre os artefatos culturais e trajetórias históricas vividas e sofridas por um povo que foi esquecido por muito tempo, uma história não apenas como simples artefato de conhecimento, mas é acima de tudo, uma reflexão de épocas que deixaram marcas. Vestir-se desse conhecer é criar aberturas para indagações e quebras de paradigmas, é contribuir na luta implacável de uma aceitação que percorre décadas, é uma constante e incansável batalha contra a não aceitação das especificidades linguísticas e cultural dos sujeitos Surdos.

A luta pela hegemonia ouvinte transcorre para o currículo ouvintista das escolas inclusivas da educação básica, tendo em vista que o aluno Surdo está no meio de ouvintes, com uma força hegemônica de cultura ouvintista, com propostas metodológicas feitas por ouvintes e para os ouvintes, e pela qual o aluno Surdo tem que se sujeitar a adaptações.

Para Apple (2006), as “[...] escolas são usadas para propósitos hegemônicos [...]”, pois incorporam o ensino dos valores culturais e econômicos, bem como suas respectivas tendências, à sua função social. O movimento de pensar e repensar em práticas educativas pedagógicas contra hegemônicas poderá proporcionar ao Surdo garantias de educação que frisem seus direitos linguísticos, sociais e morais. Uma educação mais crítica, participativa e de qualidade gera princípios democráticos, igualitários e que estejam em consonância com uma transformação social. Teixeira \& Bezerra (2007, p. 57) explicam que:

Muitos saberes são excluídos da escola por sua cultura não ter valor, por não estarem de acordo com a cultura padrão e, com isso, deixam de ser reconhecidos e são silenciados, porque o currículo ignora alguns saberes para divulgar outros que foram atribuídos como universais, de interesse de toda a sociedade. [...] Assim, a relação entre educação e cultura não pode restringir-se ao contexto do currículo, pois, dessa forma, a cultura do aluno pode ser eliminada e substituída pela predominante.

No momento em que o surdo se reconhece como indivíduo social, começa a perceber que é posto a margem de uma cultura hegemônica, pois, no instante em que o currículo assume prioridade em uma língua, que não a língua de instrução do Surdo, ou, quando a história de um povo ouvinte, toma prioridade na história de lutas do povo Surdo, está assumindo que não se reconhece a diferença. Como podemos equiparar crianças que adentram a escola já sabendo falar e se comunicar, com crianças que possivelmente ainda irão aprender esse processo?

Para essa realidade, a luta contra a hegemonia transcende a oportunidade de assumir cadeiras ocupadas por ouvintes que não façam parte da comunidade Surda e que não saibam a Libras, oportunizando, assim, discussões quanto à política educacional e pedagogia Surda. Formozo (2013, p. 107) explica que “As pedagogias surdas são um artefato cultural construído diariamente no encontro entre professores e alunos surdos, quando esse professor utiliza no espaço da sala de aula metodologias que se aproximam do que é nomeado de cultura surda".

A escola de Surdos é muito mais que um espaço físico e repasse de conteúdos, é a oportunidade de compartilhamento de experiências e de mundo, pois a maioria de Surdos são filhos de pais ouvintes não usuários da Libras, acarretando assim uma vivencia solitária para o Surdo dentro da sua base de estabilidade familiar, por tanto, é na escola que também aprendem o que não é compartilhado em família.

Mais que um lugar de saberes, a escola se torna um lugar onde a cultura Surda ganha força, um local de articulação e resistência cultural, por isso que os sujeitos Surdos precisam estar em lugar que lhes possibilite aprender com outros Surdos. Para Formozo (2013, p. 103): 
O discurso escolar perpassa as identidades surdas e a maior parte da organização das lutas surdas se dá dentro da escola, com o apoio de professores e intérpretes que ocupam os espaços ouvintes no movimento surdo, o que acaba sendo marcado pela disciplina escolar. A escola é o espaço de articulação dos mecanismos de saber e poder que definem sentidos culturais e produzem identidades. A presença de professores surdos dá ao movimento surdo um nuance pedagógico.

O contexto conteudista, por tanto, deixa de ser meramente obrigação, ganhando vida e resistência para Surdo quando estão em espaços de convívio com Surdos e com uma comunidade que entenda suas especificidades e necessidades, um momento em que o Surdo não precise de um recurso humano para poder compartilhar de ideias e duvidas junto ao professor, um espaço em que a autonomia e liberdade de comunicação seja prioridade.

Skliar (1999) alerta para o fato da educação Surda ser mais do que o uso da Libras, devendo haver um novo olhar dos ouvintes sobre os Surdos a fim de evitar "a ouvintização pedagógica, isto é, a intenção de realizar uma educação bilíngue exclusivamente a partir de professores, didáticas, textos, dinâmicas, percepções e línguas dos ouvintes monolíngues” (Skliar, 1999, p. 10).

Materiais adaptados não podem ser recursos de ensino/aprendizagem para os alunos Surdos, uma hegemonia que segue a linha de uma estrutura curricular inclusiva. O Surdo não precisa de adaptação, precisa de adequação, ou seja, materiais didáticos adequados em Libras e não adaptados da Língua Portuguesa. Como exemplo de hegemonia ouvinte, são literaturas não adequadas com histórias Surdas, a matemática é ensinada através de materiais e não através das mãos, a gramática a ser estudada é a Língua Portuguesa, e não a gramática da própria língua, a Libras.

Conteúdos, programas, organizações de tempo e espaço condicionam a estrutura escolar a considerar de modo desigual as culturas dos alunos. Quando aprendemos e/ou ensinamos, determinadas escolhas e interesses fazem com que algumas aprendizagens, pessoas e culturas sejam priorizadas em detrimento de outras. (Teixeira \& Bezerra, 2007, p. 01)

Essa priorização assume uma forte hegemonia ouvinte quando tratamos da avaliação escolar de um currículo inclusivo, pensada e exigida em Língua Portuguesa na modalidade escrita, sendo que esta é considerada a L2 do Surdo, com isso, nem adaptação, muito menos adequação. Lourenço (2017, p. 46) apresenta um relato de experiência através de sua observação de campo, referente a sua pesquisa de mestrado ${ }^{7}$, a qual explica sobre essa temática, identificando o sujeito do relato no ato da observação como "AM":

A Tradutora Intérprete havia tomado o dia de folga e, como avisado antecipadamente pelo professor de Matemática, haveria avaliação escrita e duplas de alunos; poucos minutos desvelaram as expectativas que seus colegas e também o professor da disciplina depositava em tal aluno. Nesse momento no qual os alunos escolhiam com quem gostariam de estar ao lado, AM permaneceu sozinho; organizou seu material na carteira e pôs-se a copiar do quadro as equações a serem resolvidas. Seu olhar triste começa a aflorar, sua expressão de preocupação, medo e angústia confundem-se no decorrer dos minutos. Quando terminou de copiar olhou algumas vezes para sua folha, mas não soube solucionar nenhuma das equações. Olhava para os lados, para baixo, para mim, sua expressão e seu olhar só me faziam pensar em uma palavra: solidão. Foi só aí então, que percebi o lugar, ou não lugar que esse aluno ocupa nesta sala de aula e nesta escola (Lourenço, 2013, p. 76, apud Lourenço, 2017, p. 46).

Como falar de igualdade e equidade perante uma hegemonia que percebe os Surdos pela perspectiva de deficiência, forçando sua inserção num currículo escolar que não contempla as especificidades históricas, culturais, sociais, linguística, de identidade e não contemplado pela perspectiva cultural/pedagógica e concepção socioantropológica que enfatiza a existência de ser Surdo.

\footnotetext{
7 Lourenço, K. R. C. (2013). Políticas Públicas de Inclusão: O Surdo no Sistema de Educação Básica Regular do Estado de São Paulo. Dissertação (Mestrado em Educação: Currículo). Orientador: Prof Dr Antonio Chizzotti. Pontifícia Universidade Católica de São Paulo PUC/SP.
} 


\section{Considerações Finais}

A discussão quanto às barreiras comunicacionais e os desafios presentes na sociedade vivenciados pelos Surdos é uma dificuldade que decorre pela perspectiva errônea de ver o Surdo enquanto minoria linguística, visto que a língua majoritária do Brasil é a Língua Portuguesa. Também é vivo a limitação que o Surdo enfrenta na sociedade, não havendo espaço de autonomia de diálogo nos mais diversos ambientes, como em instituições de esfera públicas e privadas, delegacias, hospitais, ministérios públicos, órgãos jurídicos, bancos, e até no meio familiar.

É constante a luta para conseguir total atendimento linguístico e por isso faz-se importante um olhar diferenciado para com o Surdo, entender sobre suas especificidades, compreender sua maneira de se perceber no mundo e de estar no mundo, dar o palco àqueles que querem nos ensinar a falar com as mãos e ouvir com os olhos, um mundo imagético que cria cenários em suas expressões e contempla cada aprender utilizando o espaço da imaginação.

É através dessa perspectiva que o currículo Surdo precisa ser posto em debate no âmbito das políticas educacionais, pois não se trata apenas de garantir inclusão escolar, é preciso proporcionar oportunidade de convívio educacional e social entre toda uma comunidade escolar, apresentamos assim, que o currículo inclusivo não atende as especificidades do alunado Surdo, uma vez que não apresenta e não valoriza a cultura, a história e as múltiplas identidades Surdas, uma vez que o currículo inclusivo se restringe a formas, moldes e modelos ouvintistas.

Doravante, discutir quanto a proposta de currículo Surdo é propiciar uma educação de conhecimentos, saberes e compreensão de mundo aos alunos Surdos. Um currículo que carrega a luta de um povo e que valoriza a língua de sinais como sendo a L1 de instrução, e a língua portuguesa como L2 na modalidade escrita, mais que isso, uma língua que transcende em todos os espaços e comunidade escolar. Com isso, apresentamos teoricamente a luta de um povo contra uma hegemonia ouvintista que nega formas de participação ativa e autônoma dos Surdos.

Consideramos que não basta somente a inclusão do aluno Surdo em salas de ensino básico regular de escolas inclusivas, faz-se necessário uma quebra de paradigmas por uma proposta educacional que respeite os Surdos pelas suas diferenças, que abrase a especificidade linguística, cultural, de identidade e de história, a fim de superar o quadro decorrente e inapropriado oriundo dos modelos educacionais atuais que não respeitam as necessidades e especificidades educacionais dos alunos Surdos.

Foucault nos ensina que as verdades são construídas discursivamente. Não há uma única verdade universal e transcendente, que espera ser desvelada por poucos desbravadores. Cada época produz seus discursos e esses discursos constroem os objetos dos quais falam. Em cada tempo e em cada espaço há o discurso permitido, as formações discursivas possíveis, as metanarrativas que não são as mesmas de outras épocas e de outros espaços, assim como há as interdições a outros discursos.

A discussão revela a necessidade de refletir quanto a inclusão escolar no ensino básico regular dos alunos Surdo, e o direito de uma comunidade que luta por outra proposta educacional de modalidade bilíngue e por políticas linguísticas, com currículo escolar que verdadeiramente considere sua especificidade visual e não os inclua como deficientes, para isso, as questões e reflexões aqui trazidas contribuem como ponto de partida para outros questionamentos. Como proposta para futuros trabalhos, pretendemos provocar novas reflexões, abordando a respeito da formação docente frente ao alunado Surdo, a atuação do profissional tradutor e intérprete de Libras educacional e a importância das políticas públicas para a representatividade da comunidade Surda nos espaços escolares.

\section{Referências}

Apple, M. W. (1995). Repensando Ideologia e Currículo. In: Moreira, A. F. B. \& Silva, T. T. (Orgs.). Currículo, cultura e sociedade. Cortez. 
Research, Society and Development, v. 10, n. 11, e424101119794, 2021

(CC BY 4.0) | ISSN 2525-3409 | DOI: http://dx.doi.org/10.33448/rsd-v10i11.19794

Brasil. (2008). Política Nacional de Educação Especial na Perspectiva de Educação Inclusiva.

Brasil. (2020). Decreto $n^{\circ}$ 10.502, de 30 de setembro de 2020. Institui a Política Nacional de Educação Especial: Equitativa, Inclusiva e com Aprendizado ao Longo da Vida.

Campello, A. R., \& Rezende, P. L. F. (2014). Em defesa da escola bilíngue para surdos: a história de lutas do movimento surdo brasileiro. Educar em Revista, 2, 71-92. Editora UFPR, https://www.scielo.br/pdf/er/nspe-2/06.pdf.

Casali, A. M. D. (2015). Educação pública: desafios à avaliação. In: SÃO PAULO. Magistério. Secretaria Municipal de Educação, 4. SME/DOT.

Feneis. (2020). Federação Nacional de Educação e Integração dos Surdos. Nota De Apoio E Esclarecimento Sobre O Decreto Da Política Nacional De Educação Especial. Documento elaborado pela FENEIS. (Texto digitado).

Feneis. (1999). Federação Nacional de Educação e Integração dos Surdos. Que educação nós surdos queremos. Documento elaborado no pré-congresso ao V Congresso Latino Americano de Educação Bilíngüe para Surdos. UFRGS. (Texto digitado).

Formozo, D. P. (2008). Currículo e educação de surdos. Dissertação do Programa de Pós-Graduação em Educação da Faculdade de Educação da Universidade Federal de Pelotas. http://guaiaca.ufpel.edu.br/bitstream/ri/2792/5/Discursos\%20sobre\%20pedagogias\%20surdas.pdf.

Formozo, D. P. (2013). Discursos sobre pedagogias surdas. Tese (Doutorado em Educação) - Faculdade de Educação da Universidade Federal de Pelotas. 159.

Foucault, M. (2005). A arqueologia do saber. Forense Universitária.

Freire, P. (2014). Pedagogia do oprimido. (57a ed.), Paz e Terra.

Goodson, I. (1995). Currículo: Teoria e História. Vozes.

Lourenço, K. R. C. (2017). Currículo Surdo: Libras na escola e desenvolvimento da Cultura Surda. Tese (Doutorado em Educação: Currículo). Pontifícia Universidade Católica de São Paulo. 257.

Lourenço, K. R. C. (2013). Políticas Públicas de Inclusão: O Surdo no Sistema de Educação Básica Regular do Estado de São Paulo. Dissertação (Mestrado em Educação: Currículo). Pontifícia Universidade Católica de São Paulo - PUC/SP.

Marconi, M. A., \& Lakatos, E. M. (2003). Fundamentos de metodologia científica. (5a ed.), Atlas.

Moreira, A. F., \& Candau, V. M. (2010). Multiculturalismo: diferenças culturais e práticas pedagógicas. Editora Vozes.

Quadros, R. M. (1997). Educação de surdos: a aquisição da linguagem. Artmed. 128.

Sacks, O. (1998). Vendo Vozes: uma viagem ao mundo dos surdos. Tradução: Laura Teixeira Motta. Cia das Letras.

Silva, T. T. (2007). Documentos de Identidade: uma introdução às teorias de currículo. (2a ed.), Autentica.

Teixeira, C. R., \& Bezerra, R. B. (2007). Escola, currículo e cultura(s): a construção do processo educativo na perspectiva da multiculturalidade. Dialogia, 6, $55-63$. 